Reprod. Nutr. Dévelop., 1988, 28 Suppl. n¹, 79-80

\title{
Effets d'une sub-carence en phosphore sur divers paramètres de l'activité cellulolytique de Bacteroides succinogenes
}

Sylvie KOMISARCZUK $\left({ }^{1,2}\right)\left({ }^{1}\right)$, Geneviève GAUDET $\left({ }^{2}\right)$, Geneviève HANNEQUART $\left({ }^{1}\right)$, G. FONTY $\left({ }^{2}\right)$, Michelle DURAND $\left({ }^{1}\right)$

(') Station de Recherches de Nutrition, I.N.R.A., 78350 Jouy-en-Josas, France.

$\left.{ }^{2}\right)$ Laboratoire de Microbiologie, I.N.R.A. Theix, 63122 Ceyrat, France.

Summary. B. succinogenes, a major rumen cellulolytic bacterium, has been cultured in a phosphorus limited medium. In addition to growth reduction, ATP concentrations and endoglucanase specific activity were severely depressed. That contributes to explain the importance of phosphorus for solid substrate degradation in the rumen.

L'extrême sensibilité de la cellulolyse à la carence en phosphore $(P)$ a été mise en évidence sur des populations mixtes de microorganismes du rumen (Komisarczuk et al., 1986 ; Komisarczuk, Merry, McAllan, 1987). L'objectif du présent travail était d'étudier les conséquences d'une sub-carence en $P$ sur la croissance et certains paramètres d'activité d'une des espèces dominantes de bactéries cellulolytiques du rumen: Bacteroides succinogenes.

Matériel et méthodes. Bacteroides succinogenes (S85) a été cultivé en anaérobiose, sur un milieu liquide contenant une dose témoin de $P$ de $100 \mathrm{mg} / \mathrm{I}$ ou une dose de sub-carence de $5 \mathrm{mg} / \mathrm{l}$ déterminée lors d'expériences préliminaires. Au cours d'une culture avec du cellobiose $(3 \mathrm{~g} / \mathrm{l})$ comme seule source énergétique, nous avons mesuré en cinétique la synthèse de protéines microbiennes par la méthode de Bradford (1976), les concentrations d'ATP par bioluminescence et l'activité endoglucanasique de la culture totale par viscosimétrie. La dégradation d'une paille traitée à la soude et de papier Whatman $n^{\circ} 1$ a été suivie pendant 12 jours en cultivant $B$. succinogenes sur le milieu de base additionné de ces substrats $(10 \mathrm{~g} / \mathrm{l})$. La dégradation de la matière sèche a été déterminée après lavages et séchage des résidus à $60^{\circ} \mathrm{C}$ jusqu'à poids constant.

Résultats et discussion. La sub-carence en $\mathrm{P}$ provoque une importante réduction de la croissance microbienne $(-65 \%)$, conséquence possible de la très faible quantité d'ATP mesurée dans la culture. Cependant, la cause principale de cette réduction pourrait être un manque d'acides nucléiques, ceux-ci consommant à eux seuls environ $80 \%$ du $\mathrm{P}$ cellulaire. L'activité endoglucanasique totale

$\left({ }^{*}\right)$ Adresse actuelle : Laboratoire de la Chaire d'Alimentation, Ecole Nationale Vétérinaire, 69752 Charbonnières. 
de la culture carencée est proportionnellement plus réduite que la croissance bactérienne, ce qui se traduit par une réduction de $20 \%$ de l'activité spécifique endoglucanasique. Cet effet stimulateur de $\mathrm{P}$ sur l'activité endoglucanasique de $B$. succinogenes est comparable à celui déjà observé sur l'endoglucanase d'une bactérie du sol : Clostridium acetobutylicum (Lee, Forsberg et Gibbins, 1985).

La sub-carence en $P$ provoque une nette réduction de la dégradation des substrats solides, qui est cependant moins intense que la réduction de la croissance sur substrat soluble. Ce résultat s'explique en partie par l'importante charge en matière microbienne des résidus solides dans les cultures témoins, qui contribue à sous-estimer les pertes de matière sèche dans ces dernières.

Cette étude a mis en évidence le rôle spécifique du $P$ sur l'activité cellulolytique de l'une des principales bactéries du rumen. Elle serait à reporter pour d'autres bactéries du rumen ainsi que pour les champignons et les protozoaires.
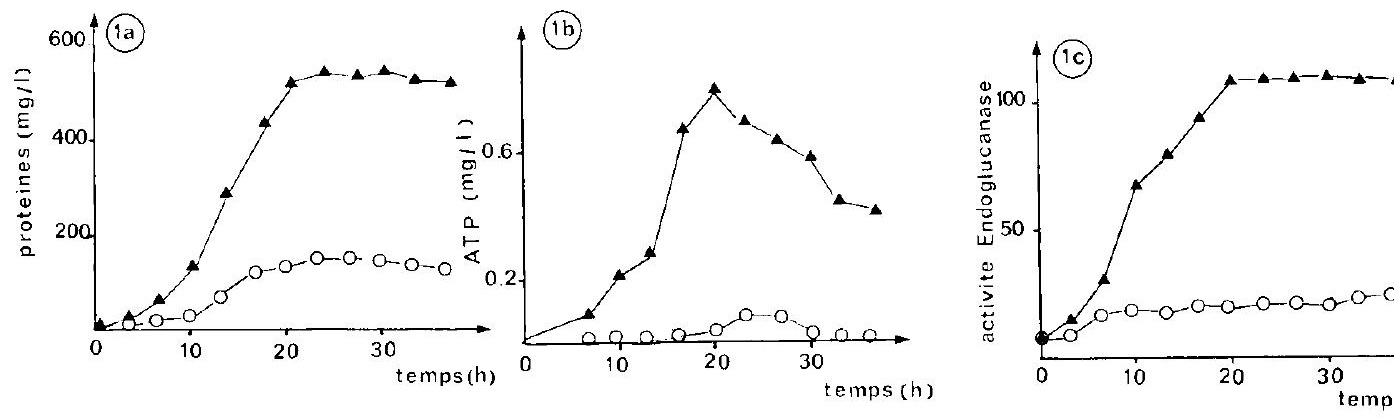

FIG. 1. - Effet de la sub-carence en phosphore sur a) la croissance, b) la concentration d'ATP et c) l'activité endoglucanase de B. succinogenes 585 . $\Delta: \mathrm{P}=100 \mathrm{mg} / \mathrm{l}::: \mathrm{P}=5 \mathrm{mg} / \mathrm{l}$.
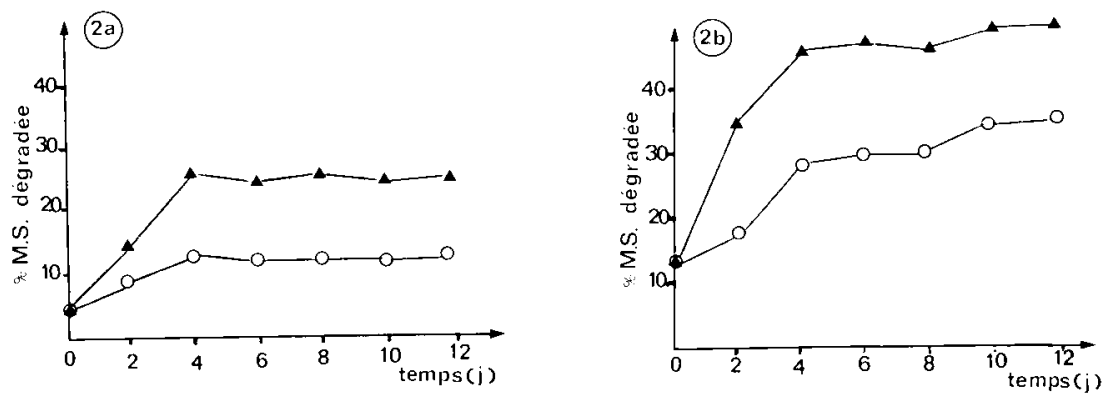

FIG. 2. - Effet de la sub-carence en phosphore sur la dégradation de substrats cellulosiques solides : a) paille traitée à la soude, b) papier Whatman $n^{\circ} 1 . \Delta: \mathrm{P}=100 \mathrm{mg} / \mathrm{l},:: \mathrm{P}=5 \mathrm{mg} / \mathrm{l}$.

Bradford M. M., 1976. Analyt. Biochem., 72, 248-254.

Komisarczuk S., Durand M., Dumay Ch., Morel M. T., 1986. In : Dubourguier H. C., Biology of anaerobic bacteria, Elsevier Sci. Publ. B.V., Amsterdam.

Komisarczuk S., Merry R. J., McAllan A. B., 1987. Br. J. Nutr., 57, 279-290.

Lee S. F., Forsberg C. W., Gibbins L. N., 1985. Appl. Environ. Micrabiol., 50, 220-228. 